\title{
Livre uso do corpo e direitos de personalidade
}

\section{Free usage of the body and personality rights}

\author{
Denis Franco Silva*
}

\section{Resumo}

O presente artigo identifica problemas relacionados ao reconhecimento de um direito ao próprio corpo como um direito de personalidade e critica os atuais modelos teóricos relativos à estrutura de tal direito, com o intuito de propor um novo modelo, baseado no paradoxo da soberania, segundo o qual a autonomia do sujeito deve ser preservada ao máximo no processo de construção da identidade pessoal.

Palavras-chave: Corpo. Direitos de personalidade. Identidade pessoal. Soberania. Autonomia.

\section{Abstract}

The present article identifies problems related to the recognition of a right to one's own body as a personality right. It criticizes the current theoretical models concerning the structure of such a right in order to propose a new model based on the paradox of sovereignty in which the agent's sphere of autonomy can be preserved as far as possible when it comes to the construction of his or her personal identity.

Keywords: Body. Personality rights. Personal identity. Sovereignty. Autonomy.

Mestrado em Direito pela Universidade Federal de Minas Gerais e doutorado em Direito pela Pontifícia Universidade Católica do Rio de Janeiro. Juiz de Fora - MG- Brasil. Email: denis. franco@ufj.edu.br 


\section{Introdução}

A temática de um direito subjetivo ao próprio corpo como um direito de personalidade, que se relaciona com a ideia de livre uso do corpo, não se apresenta de maneira trivial, mesmo no contexto de um ordenamento comprometido com a ideia de dignidade da pessoa e que conta com a previsão expressa de uma categoria de direitos subjetivos não patrimoniais, aos quais se convencionou chamar de direitos de personalidade.

A problemática da corporeidade e dos usos do corpo pode ter sua gênese nos estudos de Foucault (1979), notadamente em seu conceito de "microfísica do poder". A partir daí, ela foi sempre discutida através do prisma epistemológico do controle ou da adequação a determinados ideais de um corpo "dócil" - intimamente ligados a uma concepção objetiva de dignidade da pessoa. Ideais como os de beleza, saúde ou moralidade buscavam ser alcançados pela regulação, devendo-se ressaltar que, atualmente, como no século XIX (REIS, 1997), verificase uma aproximação cada vez maior entre a ideia de "saúde física" e "moralidade"1.

Alguns exemplos, mesmo que não pátrios, ilustram bem tal problemática. É o caso das chamadas "ugly laws" em cidades dos Estados Unidos, como Chicago, que tratava da questão no Chicago Municipal Code, Section 36.034, revogado apenas em 1974, o qual dispunha que:

Nenhuma pessoa que seja doente, mutilada ou de alguma maneira deformada a ponto de ser feia, objeto de repulsa ou pessoa imprópria, será admitida em ou sobre vias públicas ou outros lugares públicos nesta cidade, ou poderá expor a si mesma à exibição pública naqueles ou nestes lugares, sob a pena de não menos que um dólar e não mais que cinquenta dólares por cada ofensa.

Nesse sentido, interessante ver Metzl e Kirkland (2010). 
Savulesco (2007), por sua vez, relata o interessante caso de 1994 em que, por puro acaso, a polícia de Londres descobriu um ambiente no qual funcionava um clube homossexual sadomasoquista, onde, por reiteradas vezes, de forma entusiasmada e voluntária, praticaramse lesões corporais recíprocas, sempre com o consentimento dos envolvidos, nunca tendo sido feita qualquer tipo de queixa ou reclamação pelas partes. A Câmara dos Lordes concluiu que tais práticas constituíam crime.

O mais famoso dos exemplos, contudo, é, sem dúvida, o do festejado caso do "arremesso de anões", entretenimento nos bares da Commune de Morsang-Sur-Orge, Ville d'Aix-em-Provence, França. A prática, depois de decisões administrativas locais, terminou sendo proibida por decisão do Conselho de Estado (GROS; FROMENT, 1996).

Os três exemplos, de países e épocas diferentes, parecem, contudo, possuir algo em comum: uma articulação de juízos práticos ou argumentos jurídicos a partir de bases morais pré-constituídas em relação a uma prática ou a uma figura corporal socialmente desvalorizada.

Todo o discurso acerca do corpo e de suas relações com o sujeito encontra-se influenciado por um amplo espectro de compreensões conflitantes entre si e, ao mesmo tempo, complementares. Conflitantes porque, como tradicionalmente retratadas e diante de uma abordagem analítica, são autoexcludentes. Complementares porque, quando da articulação de juízos práticos, costumam-se valer da mais adequada à racionalização de intuições experimentadas diante de um problema isolado, de forma que, comumente, reduz-se a pessoa ao corpo ou a destaca completamente deste, conforme uma pré-compreensão (ou mesmo um pré-conceito) da situação concreta analisada.

Uma visão puramente racionalista do conceito de pessoa desvincula pessoa e corpo, fundamenta concepções altamente liberais no campo contratual e legitima práticas instrumentalizantes, mas que não contam com a reprovação social de cunho moral que incide sobre o arremesso de anões ou a prática de sadomasoquismo, por exemplo. 
Assim, pode-se dizer que modelos de passarela também não passam de instrumentos e são, da mesma maneira, reificados, bem como trabalhadores braçais de uma mina de carvão. Mas, destacandose pessoa e corpo, tais práticas são admitidas e legitimadas.

No caso do anão ou dos sadomasoquistas, identificam-se pessoa e corpo, reduzindo o primeiro conceito ao segundo, proibindo-se a prática da atividade por uma suposta ofensa à dignidade humana, de conteúdo objetivo (padrões de beleza, de conduta moral ou mesmo de saúde) e desvinculada da subjetividade dos principais interessados: o anão e os sadomasoquistas.

A questão da instrumentalização da pessoa através do corpo é levantada não a partir de uma compreensão da exploração do corpo em si ou das relações corpo-pessoa, mas do juízo apriorístico de se impedir a publicidade de um corpo ou um comportamento socialmente desvalorizado. Por óbvio, o reconhecimento de um direito subjetivo ao próprio corpo, dentro da estrutura dos direitos de personalidade, não pode traduzir tal abordagem.

Busca-se, portanto, apresentar uma estrutura para o direito subjetivo ao próprio corpo, na qual o direito de personalidade não se configure como uma mera proteção à integridade física, a partir de processos de normalização de seu conteúdo pela coletividade. Ademais, busca-se um modelo de compreensão do direito ao próprio corpo que pressuponha a autonomia da pessoa como fundamento.

\section{0 direito ao próprio corpo como um direito de personalidade}

O conceito de pessoa normalmente é definido a partir das características de racionalidade autônoma, alteridade (entendida como encontrar-se em relação, ou seja, uma postura de abertura ao outro e ao mundo) e individualidade.

Tal descrição pressupõe certa estabilidade, caso se pretenda avançar para além de um mero conceito formal e apreender, ao menos em certa medida, a substância do ente qualificado como pessoa. 
Essa estabilidade, ao longo do tempo, constitui a identidade pessoal, comumente definida em termos de continuidade de estados psicológicos e autoconsciência reflexiva².

A identidade pessoal, constituída basicamente pela associação entre a mente e um repertório de condutas - interiores ou exteriores - é o que permite, através de um corpo, a inserção da pessoa no tempo e no espaço.

Sendo "pessoa" um conceito descrito a partir das ideias de autonomia, intersubjetividade e individualidade, e sendo a identidade pessoal algo essencialmente dinâmico, dificilmente se poderia compatibilizar tal descrição com uma percepção estática acerca dos direitos de personalidade que articule a proteção à pessoa ou à personalidade a partir de paradigmas teórico-dogmáticos típicos de relações patrimoniais, como o direito de propriedade. Isso se revelaria insuficiente não apenas pelo aprisionamento em fattispecies fechadas - as quais traduzem a falsa ideia de que se poderia acomodar uma realidade multifacetada e complexa como a pessoa em um conjunto de enunciados independentes e não comunicáveis entre si -, mas, principalmente, porque pressupõe uma determinação prévia do que é objeto de tutela, bem como dos limites dessa tutela e de seus mecanismos (BODIN DE MORAES, 2008).

Aceita-se como premissa teórica, portanto, a ideia de uma cláusula geral de tutela da pessoa ou de um direito geral de personalidade, identificando-se a proteção da personalidade com a proteção à identidade pessoal e promoção de seu livre desenvolvimento ${ }^{3}$.

Nesse ponto, convém observar que nem todas as tradicionais características atribuídas aos direitos de personalidade como traços distintivos de uma categoria específica de direitos subjetivos são

Para uma discussão acerca dos efeitos normativos da projeção temporal da identidade pessoal, veja-se Wrigley (2007).

3 Nesse sentido, veja-se Capelo de Souza (1995). No Brasil, por todos, Tepedino (2001). 
propriamente aplicáveis em sua integralidade ao tratar-se de um direito subjetivo ao próprio corpo. Notadamente, as chamadas características de indisponibilidade e irrenunciabilidade, decorrentes da ideia de inalienabilidade, não se podem revelar presentes, como normalmente se pressupõe $e^{4}$.

A proteção aos chamados direitos de personalidade corresponde à proteção da chamada identidade pessoal em suas mais diversas manifestações, seja a liberdade religiosa e/ou sexual, seja o reconhecimento de um direito subjetivo sobre o próprio corpo, uma das formas de concretização espaço-temporal dessa identidade que não se pode pré-determinar, constitui-se de maneira autônoma e se caracteriza pela mutabilidade.

Não existe, portanto, conceitos pré-estabelecidos de vida boa ou ideais de bem objetivamente considerados, a partir dos quais se materializa a proteção dos direitos de personalidade. Essa proteção é conferida, na verdade, à identidade pessoal que cada um apresenta como materialização de um conjunto de hiperbens, ou seja, o conjunto de valores, ideais e aspirações que orienta a pessoa e permite a atribuição ou o reconhecimento de uma identidade pessoal específica a alguém (TAYLOR, 1997). Tais hiperbens, como afirma Taylor (1985), são valores produtos de uma avaliação forte, desejos e escolhas que envolvem discriminações acerca do certo e errado, pior ou melhor, em uma perspectiva subjetivista.

É esse conjunto de hiperbens que oferece orientações a partir das quais a pessoa se afirma perante si e perante outros, por meio de ações carregadas de significado pelos hiperbens cultivados, não sendo estes apenas projeções, mas constitutivos da personalidade, no sentido substancial, em que é protegida pela estrutura dos direitos de personalidade. Busca-se justamente, através do reconhecimento da categoria dos direitos de personalidade, evitar a sujeição de um conjunto

\footnotetext{
4 Sobre a questão da renúncia ao exercício de direitos de personalidade, bem como da prática de atos de disposição, veja-se Stancioli (2010).
} 
de identidades pessoais minoritárias aos desígnios de uma maioria. Algo intrinsecamente ligado, portanto, à própria ideia de democracia.

Falar em um direito ao próprio corpo é, portanto, falar em dignidade subjetiva, em proteção a um direito de personalidade e a uma personalidade específica, bem como em sua inserção dentro de uma esfera de administração e disposição privada de interesses juridicamente protegidos no âmbito de uma cláusula geral de tutela e proteção da pessoa, presente em nosso ordenamento através do disposto no artigo $1^{\circ}$, inciso III, da Constituição Federal de 1988.

\section{Como se subjetiva o direito ao próprio corpo?}

O direito ao próprio corpo é frequentemente citado pela doutrina como um dos direitos de personalidade, possuindo a estrutura de um direito subjetivo. As codificações, ao tratarem de direitos de personalidade, preveem ou pressupõem, através de dispositivo específico, um direito ao corpo ${ }^{5}$. Entretanto, cabe indagar de que forma se subjetiva tal direito, tema que muitas vezes não é explorado pela maioria dos autores, pois, normalmente, a atenção legislativa ou doutrinária a ele destinada se refere exclusivamente aos limites a esse direito subjetivo, sempre estabelecidos a partir de um conceito objetivo do bem jurídico a ser tutelado ${ }^{6}$.

A preocupação com o estabelecimento de limites, traçados a partir de uma perspectiva objetiva de proteção à pessoa, não se coaduna com a visão dos direitos de personalidade exposta, de modo que se deve abordar a questão do direito sobre o próprio corpo em uma perspectiva dinâmica.

Nesse sentido, cabe observar que a pouca atenção destinada à maneira como se subjetiva o direito ao próprio corpo se deve à admissão,

Veja-se, como exemplo, além do Código Civil brasileiro, o Código Civil italiano (art. $5^{\circ}$ ) e o Código Civil português (art. $\left.70^{\circ}, 1\right)$.

$6 \quad$ Vide, como exemplo e por todos, no Brasil: Pereira (2004); em Portugal: Neto (2004); e na Itália: D’Arrigo (1999). 
explícita ou implícita, de que tal direito se estrutura da mesma maneira que outros direitos subjetivos, notadamente, o direito de propriedade.

Na doutrina anglo-saxônica, tal perspectiva é disseminada de forma explícita, reconhecendo-se um direito de self-ownership (propriedade de si) no que se refere à proteção ao corpo, claramente construído em analogia ao direito de propriedade (ARCHARD, 2008). A proteção à integridade física se daria, então, da mesma maneira que a proteção à propriedade de determinada área: como algo externo à pessoa (no que se identifica uma postura dualista racionalista, desvinculando o corpo da pessoa e vendo-o como objeto sobre o qual ela exerce poderes ou controle).

Isso significa que, garantidas certas prerrogativas quanto a não violação dos limites espaciais sobre os quais incide tal direito, a questão acerca da forma pela qual se admite a disposição do próprio corpo assume a mesma perspectiva daquela relativa ao direito de propriedade: uma ponderação no que tange à utilidade ou instrumentalidade do bem, seu valor de uso e de troca, valor individual e social, em que o legislador submete ou não determinados bens a um regime de disposição diferenciada? .

Dessa maneira, o proprietário (pessoa), possuindo uma garantia de não violação por trespasse de determinadas fronteiras de um espaço exterior a si (o corpo), frui e dispõe do bem dentro dos limites estabelecidos pela comunidade.

Tal modelo pode ser identificado como predominante quanto à proteção ao corpo na doutrina brasileira (nesse caso, de maneira implícita), embora profundas críticas já tenham sido feitas quanto à utilização de um modelo de proteção preocupado com objetos externos ao sujeito e de caráter patrimonial para a compreensão da categoria dos

\footnotetext{
7 Por exemplo, o bem de família, previsto nos arts. 1.711 e seg. do Código Civil de 2002 ou a ideia de patrimônio mínimo, conforme exposta por Fachin (2006).
} 
direitos de personalidade ${ }^{8}$. Tradicionalmente, confere-se ênfase em ter um corpo, e não em ser um corpo.

Uma alternativa a esse modelo de compreensão do direito ao próprio corpo não pode, todavia, voltar-se exclusivamente à ideia de ser um corpo, reduzindo-se a pessoa ao corpo. A relação que se possui com o corpo, protegida juridicamente, não é simplesmente de possessão, tampouco de identidade. Acredita-se, assim, que uma melhor compreensão da maneira pela qual se subjetiva o direito ao próprio corpo pode ser alcançada através de uma analogia com o paradoxal conceito de soberania ${ }^{9}$. De acordo com Agamben (2002, p. 23), o paradoxo da soberania se enuncia da seguinte forma:

[...] o soberano está, ao mesmo tempo, dentro e fora do ordenamento jurídico. Se o soberano é, de fato, aquele no qual o ordenamento reconhece o poder de proclamar o estado de exceção e de suspender, deste modo, a validade do ordenamento, então 'ele permanece fora do ordenamento jurídico e, todavia, pertence a este'

A especificação não é trivial: o soberano, tendo o poder legal de suspender a validade da lei, coloca-se legalmente fora dela. O paradoxo pode ser formulado também deste modo: "a lei está fora dela mesma", ou então: "eu, o soberano, que estou fora da lei, declaro que não há um fora da lei”(AGAMBEN, 2002, p. 23).

Neste aspecto, é certo que o ordenamento regula o chamado direito ao próprio corpo. Todavia, ao titular desse direito, se conferida

\footnotetext{
Veja-se, por todos, Bodin de Moraes (2008) e Tepedino (2001).

Um paralelo entre os direitos de personalidade e a noção de soberania já foi sugerido por Villela (2004). Da mesma maneira, a visão do right of self-ownership, do Direito anglo-saxão, encontra, além de formulações a partir da ideia de propriedade, opiniões que o justificam, com base na ideia de soberania, como expõe Archard (2008) e Mill (1974), que utilizava a mesma expressão no que se refere ao direito sobre o próprio corpo. Cabe observar, no entanto, que tais paralelos à ideia de soberania baseavam-se exclusivamente na analogia com a relação entre um soberano e a área territorial sobre a qual ele exerce poderes, para justificar a vedação ao trespasse do limiar entre o dentro e o fora como ato ilícito, de forma muito próxima, senão análoga, ao chamado right of self-ownership.
} 
posição análoga à de soberano (que, como ocorre com os modernos Estados nacionais, é constituído por e possuidor de um território ou uma delimitação espaço-temporal), permite-se que este se coloque em estado de exceção à regra, decidindo, a partir de sua autonomia, acerca da inclusão ou exclusão da ação perpetrada sobre o corpo, nos limites do direito vigente.

Obviamente, o reconhecimento de tal soberania sobre si e, consequentemente, sobre sua extensão espacial-temporal (o corpo) somente produz efeitos dentro de estritos limites, estabelecidos pelos espaços de soberania adjacentes e por um espaço sobre qual o indivíduo ou qualquer outro não é reconhecido como detentor de poderes de soberania de forma individual, mas somente coletiva, através do Estado.

Ao legislador, portanto, cabe a tarefa de regular esse espaço relacional existente entre núcleos de soberania distintos no que se refere ao direito ao corpo. Todo e qualquer comportamento de um agente que invada sem consentimento o espaço de soberania do outro é considerado uma ofensa. Da mesma forma, toda e qualquer ação que produza consequências no espaço entre os núcleos de soberania constituídos por pessoas individualmente consideradas se encontra sob o império do direito estabelecido. Por sua vez, toda e qualquer ação ou comportamento que não ultrapasse os limites espaço-temporais da soberania exercida pela pessoa sobre o próprio corpo será incluída ou excluída da esfera de incidência da norma, em conformidade com a vontade do soberano, nesse caso, a própria pessoa.

Uma análise do artigo 13 do Código Civil de 2002 certamente poderá melhor elucidar o que aqui se propõe. Eis o texto:

Art. 13. Salvo por exigência médica, é defeso o ato de disposição do próprio corpo, quando importar diminuição permanente da integridade física ou contrariar os bons costumes.

Parágrafo único. $\mathrm{O}$ ato previsto neste artigo será admitido para fins de transplante, na forma estabelecida em lei especial. 
Sob o prisma dessa concepção, os atos de disposição acerca do próprio corpo devem ser analisados quanto ao seu enquadramento na norma em três hipóteses distintas, quais sejam: i) o ato de disposição não transcende os limites de exercício do poder soberano da pessoa; ii) o ato de disposição transcende os limites de exercício do poder soberano da pessoa e invade a esfera de soberania pessoal de outra; iii) o ato de disposição transcende os limites de exercício do poder soberano da pessoa, inserindo-se, ainda que mediante autorização, na esfera de soberania de outro e produz consequências relevantes na esfera pública relacional.

Quanto à primeira hipótese, o ato de disposição não poderia, ceteris paribus, ser tratado como ilícito ou contrário ao Direito, visto que, incluindo-se o soberano, ou seja, a própria pessoa, no ordenamento pela situação de exceção em relação à norma estabelecida para os demais, cabe a ele a decisão acerca do ato a ser praticado sobre o próprio corpo.

Cita-se como exemplo uma cirurgia de retirada dos seios em um indivíduo transexual secundário do sexo feminino. Embora permanente e, na visão de muitos, contrária aos "bons costumes", não se pode objetar ao procedimento com base na suposta indisponibilidade do corpo.

$\mathrm{Na}$ segunda hipótese, o ato de disposição, ao transcender a esfera de soberania do agente e penetrar na de outro, seria admissível, dependendo da forma pela qual ele fosse recepcionado pelo outro agente soberano, em uma espécie de "abertura recíproca de fronteiras".

É o caso dos sadomasoquistas de Londres, no qual a Câmara dos Lordes decidiu que a prática de sadomasoquismo constituía crime por tratar-se de uma questão de interesse público, apesar do consentimento das partes envolvidas. Obviamente, o "interesse público" na preservação da saúde e prevenção das lesões recíprocas nada mais é do que preconceito em relação a um modelo de vida sexual discrepante daquele imposto pelos chamados "bons costumes" em um país onde o boxe é esporte popular.

Certamente, não são as lesões recíprocas e consensuais à integridade física o que se encontra por trás do animus decidendi. Em 
situações como essa, somente poderia haver intervenções à autonomia das partes envolvidas em caso de invasão da esfera pública, com a produção de consequências negativas a terceiros, o que não ocorreu.

Tendo as vítimas "aberto as fronteiras de seu corpo" através do consentimento, e não apenas permitido como desejado a violência em nome de um bem por eles tido como mais importante do que a integridade física, qual seja, o prazer sexual, não se poderia falar em ofensa ou abuso de um direito ao corpo.

Já na terceira hipótese, ainda que o ato de disposição seja recepcionado por outra pessoa, pelo fato de produzir graves consequências no espaço relacional intersubjetivo, submete-se ele ao direito vigente, somente sendo autorizado se presentes as condições previstas no artigo 13 do Código Civil de 2002.

Cita-se como exemplo a venda de um rim. Embora ambos os agentes (vendedor e comprador) estejam, a princípio, de acordo com o ato de disposição, a admissão de tal prática desvirtuaria de forma completa os objetivos de um sistema igualitário e altruístico de distribuição de recursos biomédicos, essencial, talvez, para que o direito à saúde seja uma prerrogativa não dependente (ou menos dependente) da situação econômica do paciente, pelo que seria tido como inválido o ato de disposição do corpo, por ser ele uma diminuição permanente da integridade física contrária aos bons costumes (no caso, a ofensa concretiza-se na contraprestação pela "doação" do órgão, que frustra as políticas públicas orientadas à universalização do acesso à saúde, independentemente de classe social). Tal ato seria proibido, mesmo na eventual ausência de vedação expressa pela atual lei brasileira de transplantes de órgãos e tecidos ${ }^{10}$.

Fundamenta-se o exposto no que se pode denominar amplamente de pensamento moral contemporâneo, projetando-se para o âmbito de toda razão prática e acatando-se a tese do discurso jurídico como

$10 \quad$ Lei $n^{\circ} 9.434$ de 04 de fevereiro de 1997. 
um caso especial da razão prática (ALEXY, 1997). Ele se concretiza a partir de três eixos distintos: os direitos e obrigações perante outros, o conceito de vida plena ou vida boa e a ideia de respeito atitudinal - o motivo pelo qual cada um se sente digno de respeito por si e pelos outros (TAYLOR, 1997).

É interessante observar que é justamente o primeiro eixo que se desenvolveu em nossa sociedade, através do mecanismo de atribuição de direitos e deveres jurídicos, ou seja, através da ideia de direitos subjetivos conferidos aos cidadãos, sendo destinados, por sua vez, diretamente à esfera da autonomia moral individual os outros dois eixos restantes: a concepção de vida boa e de respeito atitudinal, intimamente relacionados à identidade pessoal que se pretende construir.

Isso se deve ao fato de que as concepções de vida plena a serem adotadas ou os juízos individuais acerca daquilo que confere a alguém valor ou dignidade intrínseca encontram-se no centro da esfera de soberania individual, somente podendo sofrer interferências quando há "transbordamento" para a esfera pública.

\section{Conclusão}

Esse modelo de analogia entre o direito ao corpo e a ideia de soberania, conforme exposta por Agamben (2002), diferencia-se das tradicionais concepções e parece mais adequado basicamente por duas razões: i) não pressupõe que o corpo seja um objeto externo ao sujeito, sobre o qual este detém poderes conferidos pelo ordenamento, como ocorre na estrutura do direito de propriedade. O direito ao próprio corpo, portanto, não pode ter seu conteúdo limitado a partir de concepções coletivas acerca do belo, do saudável ou do normal; ii) não se tratando a autonomia de um direito, mas de um pressuposto ou capacidade implícita ao status de pessoa (NINO, 1992; HABERMAS, 2005), que se exterioriza e se concretiza em maior ou menor grau através de estruturas conhecidas como direitos subjetivos, oferece-se uma estrutura dentro da qual esse pressuposto pode encontrar a maior amplitude possível. 


\section{Referências}

AGAMBEN, Giorgio. Homo sacer: o poder soberano e a vida nua I. Tradução de Henrique Burigo. Belo Horizonte: UFMG, 2002.

ARCHARD, David. Informed consent: autonomy and self-ownership. Journal of applied philosophy, Aberdeen, v. 25, n. 1, p. 19-34, 2008.

BODIN DE MORAES, Maria Celina. Ampliando os direitos de personalidade. In: VIEIRA, José Ribas (Org.). 20 anos da constituição cidadã de 1988: efetivação ou impasse constitucional? Rio de Janeiro: Forense, 2008. p. 369-388.

D'ARRIGO, Cosimo M. Autonomia privata e integritá física. Milano: Giuffrè, 1999.

FACHIN, Luiz Edson. O estatuto jurídico do patrimônio mínimo. 2. ed. Rio de Janeiro: Renovar, 2006.

FOUCAULT, Michael. Microfísica do poder. Rio de Janeiro: Graal, 1979.

GROS, Manuel; FROMENT, Jean Charles. Composantes jurisprudentielles de la notion d'ordre public. Revue du Droit Public et de la science politique en France et à l'étranger, Paris, n. 2, p. 536568, mars/avril 1996.

HABERMAS, Jürgen. Facticidad y validez: sobre el derecho y el estado democrático de derecho em términos de teoría del discurso. 4. ed. Madrid: Trotta, 2005.

METZL, Jonathan M.; KIRKLAND, Anna (Org.). Against health: how health became the new morality. New York University Press, 2010.

MILL, John Stuart. On liberty. Harmondsworth: Penguin, 1974.

NETO, Maria Luísa. 0 direito fundamental à disposição sobre o próprio corpo: a relevância da vontade na configuração do seu regime. Coimbra: Coimbra Editora, 2004. 
NINO, Carlos Santiago. La autonomia constitucional. In: ROSENKRANTZ, Carlos F. et al. La autonomia personal. Madrid: Cedam, 1992. p. 33-81.

PEREIRA, Caio Mário da Silva. Instituições de direito civil. 20. ed. Rio de Janeiro: Forense, 2004. v.1.

REIS, João José. O cotidiano da morte no Brasil oitocentista. In: ALENCASTRO, Luís Felipe de (Org.). História da vida privada no Brasil: império: a corte e a modernidade nacional. São Paulo: Companhia das Letras, 1997. p. 94-141.

SAVULESCU, Julian. Autonomy, the good life and controversial choices. In: RHODES, R.; FRANCIS, L. P.; SILVERS, A. (Org.). The blackwell guide to medical ethics. Oxford: Blackwell Publishing, 2007. p. 17-37.

SOUZA, Rabindranath V.A. Capelo de. O direito geral de personalidade. Coimbra: Coimbra Editora, 1995.

STANCIOLI, Brunello. Renúncia ao exercício de direitos da personalidade ou como alguém se torna o que quiser. Belo Horizonte: Del Rey, 2010.

TAYLOR, Charles. As fontes do self: a construção da identidade moderna. Tradução Adail Ubirajara Sobral e Dinah de Abreu Azevedo. São Paulo: Loyola, 1997.

TAYLOR, Charles. Human agency and language: philosophical papers 1. Cambridge: Cambridge University Press, 1985.

TEPEDINO, Gustavo. A tutela da personalidade no ordenamento civilconstitucional brasileiro. In: de Janeiro: Renovar, 2001. p. 23-54.

Temas de direito civil. 2. ed. Rio

VILLELA, João Baptista. Direitos de personalidade negativos: por que não? Tabulae: Revista da Faculdade de Direito da Universidade Federal de Juiz de Fora, Juiz de Fora, v. 21, p.1-15, 2004.

WRIGLEY, Antony. Personal identity, autonomy and advance statements. Journal of Applied Philosophy, Oxford, v. 24, n. 4, p. 381-396, 2007.

Recebido em: 00/11/13

Aprovado em: 00/12/13 